\title{
Toxicity Grade Code
}

National Cancer Institute

\section{Source}

National Cancer Institute. Toxicity Grade Code. NCI Thesaurus. Code C93695.

A coded value specifying the numeric grade for the toxicity. 